\title{
A mixed-model multi-objective analysis of strategic supply chain decision support in the Thai silk industry
}

\author{
Natawat Jatuphatwarodom* \\ Department of Textiles and Clothing, Rajamangala University of Technology, Thanyaburi, Thailand, \\ Dylan F. Jones, Djamila Ouelhadj \\ Centre for Operational Research and Logistics, Department of Mathematics, University of Portsmouth, \\ Lion Terrace, Portsmouth, PO1 3HF, United Kingdom.
}

\begin{abstract}
This paper presents a methodology for combined usage of data envelopment analysis (DEA), analytical hierarchy process (AHP) and extended goal programming (EGP) in order to provide managerial decision support. The methodology allows the three techniques to be used in a coordinated manner to give an enhanced level of holistic decision support. DEA is first used in a descriptive sense in order to provide information regarding the efficiency of a set of units. The AHP is then used in order to determine the importance of criteria arising from decision problem(s) related to the improvement of unit efficiency. Finally, EGP is used in a prescriptive sense in order to select a set of specific actions for improving unit efficiency.

Two specific multi-objective situations arising from the Thai Silk industry are used as case studies for the proposed methodology. These involve supplier selection and inventory management system management in the presence of multiple conflicting goals and objectives. In the case studies, DEA is used to provide efficiency estimates of current suppliers and processes. AHP is then used in order to determine the relative importance of criteria for supply chain efficiency improvement. Adaptations are made to an automated inconsistency reduction algorithm in order to resolve high levels of inconsistency found. The relation between decision maker confidence and consistency is investigated. Finally, an EGP model is built in order to suggest improvement actions to the supply chain processes. Results are given for a set of eight Thai silk manufacturers and conclusions are drawn.
\end{abstract}

Keywords Thai silk industry, goal programming, analytic hierarchy process, data envelopment analysis, supply chain management.

\author{
1. Introduction \\ * Corresponding author: Dr. Natawat Jatuphatwarodom, Rajamangala University of Technology \\ Thanyaburi, 39 Moo 1, Rangsit- Nakhonnayok Road, Thanyaburi, Pathum Thani, \\ Thailand 12110, natawat i@rmutt.ac.th, Tel: +66 025493333
}


The textile industry plays a significant role in the manufacturing and production base of many middle-income nations. For instance Thailand has a significant textile and clothing export industry. However, in common with many similar nations, there are significant external pressures that lead to the need to make process and product efficiencies. Thailand's Deputy Prime Minister and Minister of Industry suggests that "there is more intense competition in the global market, there is a need for Thai textile and clothing entrepreneurs to adjust and make strategic changes as well as to develop new products and increase value added to be competitive in the market" (Watchravesringkan, 2009). Thus, it is important to understand how global competitors and trade liberalization affect the future of this industry and what strategic adaptations can be used to reduce constraints in order to respond to global competitiveness. When considering the most well-known type of textile and fabric in Thailand, Thai Silk is usually the first material considered. Silk fabric is one of the important products of Thailand from an international viewpoint.

One key area in many middle income nations that has received recent governmental support is that of logistics and supply chain management. In Thailand, the government and the private sector are also concentrating on making the industry more competitive by encouraging further innovations, modernizing technology for greater efficiency, and improving the skill and competency of the nation's garment and textile businesses (Department of International Trade Promotion, 2011). The goals of this paper are to (i) develop a methodology for combining the DEA, AHP and EGP techniques in order to provide an enhanced level of decision support for managerial strategic decision making and (ii) to use the developed methodology to enhance strategic decision support in the logistics and supply chain management functions of the Thai Silk sector. A number of companies are liaised with in order to undertake the primary research for the second goal. There are eight representative Thai silk manufacturers involved. Multiple criteria models are used in this research to measure and enhance the efficiency of a set of major Thai silk manufacturers' existing supplier selection and inventory management processes. The multi-criteria models used in the research are as follows: The AHP is used for optimal decision making for the manufacturers' key decision makers, DEA is used for measuring efficiency for manufacturers (existing suppliers and inventory management), and EGP is used for optimizing planning decisions in the presence of multiple conflicting objectives regarding inventory management, since each of manufacturers need to make multiple decision choices in order to solve their existing problems.

The main objectives of this paper are:

- To combine the techniques of DEA, AHP and EGP in a symbiotic manner in order to provide a level of holistic decision support beyond that given by the single use of any of the three individual techniques.

- To identify key strategic decision problems and their respective multiple decision-making criteria pertaining to the logistics and supply chain management functions of the Thai Silk industry.

- To use the integrated DEA, AHP and EGP methodology to prescriptively suggest sets of improvements to Thai Silk companies supply chain and inventory management processes

The remainder of this paper is organized as follows. Firstly, a literature review (Section 2) is written about a relative philosophy of Thailand textile industry, the Thai silk industry and its markets, and key issues such as product problems, inventory management problems, and supply chain problems as well as of the techniques of DEA, AHP and EGP and their combination. Secondly, the methodology section (Section 3) details the approaches of this particular research and its structure. Thirdly, the next three sections (Sections 4-6) present the DEA, AHP and EGP models applied to the case studies. Finally, the discussions and conclusions Section (Section 7) draws out the major contributions and recommendation points of this paper.

\section{Literature review}




\subsection{Thailand Textile Industry Overview}

The Thai government has established a consortium for SMEs (Small and medium-sized enterprises), supported by the Department of Export Promotion to develop the internationalization potential of Thailand's 80,000 small and medium enterprises in the Thai textile industry (Johnsen, 2007). Silk represents a high value export from Thailand to international markets each year. However, the Thai Ministry of Agriculture and Cooperatives has identified constraints that limit the expansion of Thailand's silk sector, in international markets and trading networks. Thai silk production and processing are highly labor intensive activities and are suffering from competition from countries with lower costs such as China and India. These countries in recent years have invested in manufacturing methods, management and marketing systems, which have increased the competitive pressures on Thailand's industry. In addition to offering more opportunities such as the expansion of markets to the ASEAN (The Association of Southeast Asian Nations), globalization and textile and apparel trade liberalization have posed many challenges to Thailand's textile and clothing industry. Additionally, there is growing intensive competitiveness from China and other Asian countries (e.g. India, Vietnam) (Watchravesringkan, 2009). Through a variety of programs, Thailand's Department of Export Promotion (DEP) has assisted manufacturers to keep abreast of evolving international fashion trends and produce materials that meet global demand, such as bringing a textile specialist from Italy to Thailand to advise on conceptual trends and styles (Department of International Trade Promotion, 2011).

\subsection{Market Analysis}

Historically, the US has been the top importer of Thai textile and apparel products, followed by the EU, ASEAN, and Japanese markets. The imports of fabrics, particularly silk and wool/animal hair products, have consistently increased. In terms of the silk industry, silk represents a tiny percentage of the global textile fiber market. Silk is a premium priced agricultural commodity; the unit price of raw silk is roughly twenty times that of raw cotton. Thailand is the sixth largest raw silk producer with about $1 \%$ of the world production and is ranked seventh in term of raw silk imports (about 3\% of the world imports). Thailand, being one of the world's leading textile producers, is dependent on imported raw silk to meet the demands from the textile industry due to limited domestic supplies (Watchravesringkan, 2009). It appears difficult to predict global consumption trends of silk. This is because silk products tend to share the characteristics of luxury products, which are not very sensitive to price changes. In the long run, demand is affected by factors such as fashion trends, promotion, and changing attitudes of the public toward natural fibers and textile products. Promotion of silk and natural fiber can have a major effect on demand and attitudes of consumers. The next section discusses the Thai silk industry.

\subsection{The Thai Silk Industry}

Thailand has a millennia-old tradition of silk production that has survived up to the present day because of the country's relatively stable economic environment (Graham, 2011). In Thailand, the large majority of such farmers are located in the northeast of the country. The weaving, dying and printing of fabric constitute the midstream industry. The largest categories of silk exports are woven fabrics and yarn (Patichol, 2014). Major export markets of Thailand include the USA, Japan and the UK. Thailand also imports industrial silk yarn and fabric, mainly from China and India (Patichol, 2014). Thailand's silk industry in the northeast area can be classified into three sections as, Upstream supply chain (Sericultural farmers, Reeling activities), Middle stream supply chain (silk yarn producers weavers), and Downstream supply chain (final product producers, marketers/ traders) (Siewsamdangdet et al, 2010, detailed in figure 1). Figure 2 also represents the overall stakeholder breakdown in the industry which consists of farmers, silk yarn producers, weavers, final product producers, and marketers. The total number of people involved is about 450,000 within the Thai silk industry itself. The largest section is farmers at around 136,884.

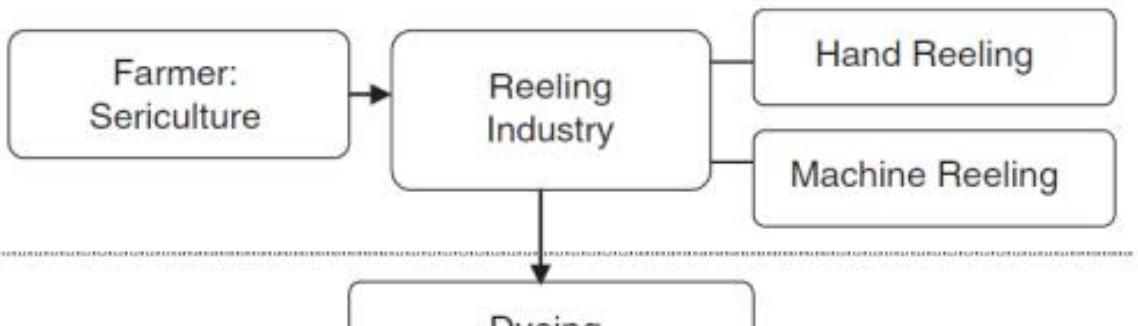


Fig 1 Overview of Thai silk supply chains

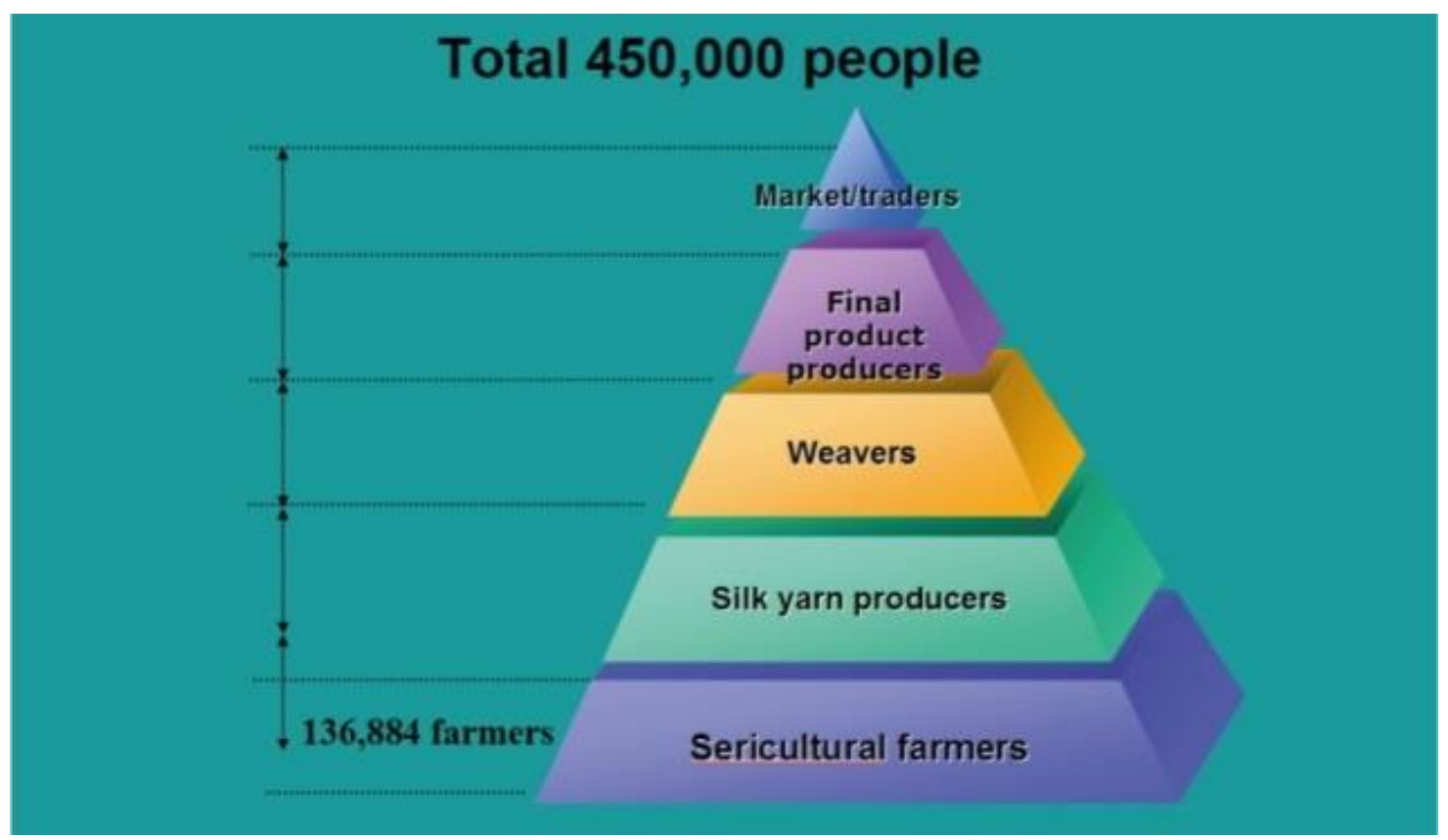

Fig 2 Stakeholders of the Thai Silk Industry.

Komolavanij et al (2008) identify the major problems discovered in many clothing and textile factories based on a case study approach. One highlighted case study is the production processes of the product in the Classic Model Co., Ltd Company. The selected product is the Thai silk Jeans. The researchers use analysis techniques as follows: Value Stream Analysis, Swim lane Diagram, and Activity-Based Costing (ABC). In conclusion, at the end of the study, the researchers had identified the major problems in the manufacturer as 
follows Product Problems, Inventory Management Problems, Management Problems, Marketing Problems and Supply Chain Problems. The mentioned problems were the major objectives to which the key decision makers should pay attention. Jantaka and Tangjaturasopon (2012) study how to remove barriers of primary activities for supply chain processes of Thai silk products. The method is interviews of silk enterprises in a specific zone with total of 117 people involved. The benefit of the research is to identify a variety of barriers in primary activities for the Thai silk supply chains, to be taken by the related agencies for further development. Promsaka Na Sakolnakorn (2009) presents the management strategy for administration of textile industries in Thailand. The purpose of this particular research is to identify significant problems with the manufacturing and inventory management of the textile industry in northeast Thailand and suggest a management strategy that will solve those problems. The findings reveal that there were six influences on the organizational development of textile industries: 1) human resource management, 2) financial performance, 3) knowledge capital, 4) marketing management, 5) supply chain management, and 6) Inventory management.

\subsection{DEA, AHP, Goal Programming (GP) and their integrated use.}

This subsection reviews the three multi-criteria techniques that comprise the integrated methodology proposed in this paper to assist Thai silk decision makers. Each technique is reviewed in turn, considering its usage in real-world problems with an emphasis on those similar to the case study of this paper. The integration of the techniques found in the literature is then considered.

\subsubsection{DEA}

DEA is a well-established technique used to measure the relative efficiency of a set of similar units with reference to their inputs and outputs Charnes et al, (1978). A detailed description of the methodological stateof-the art in DEA is given by (Zhu, 2016). DEA has been widely applied across a range of fields, examples of which that show similarity to the case study in this paper are detailed in the remainder of this subsection. Ouenniche and Tone (2017) apply a DEA to bank performance measurement, including out-of-sample measurement techniques. Garfamy (2006) proposes and demonstrates the application of DEA approach in evaluating the overall performances of suppliers on multiple criteria based on total cost of ownership (TCO) concept and simulated data in a hypothetical firm and with a strategic orientation of being able to reduce TCO by identifying benchmark values. Petridis et al. (2017) provide a DEA-based methodology for optimal design of supply chain networks.

\subsubsection{AHP}

The AHP is a widely used discrete-choice multi-criteria decision making technique can be used to elicit relative importance weights from a set of criteria via pairwise comparisons. It has the strengths of ease-ofuse and its ability to measure inconsistency in the judgements of the decision maker. The AHP has been widely applied across a range of fields, of which some applications bearing similarity to the case study of this paper are detailed in the remainder of this paragraph. Wang et al. (2004) propose an integrated AHP and pre-emptive goal programming (PGP) based multi-criteria decision-making methodology to take into account both qualitative and quantitative factors in supplier selection. Zaim et al. (2012) propose the AHP and the Analytical Network Process (ANP) for the selection of the most appropriate maintenance strategy in a local newspaper printing facility in Turkey. Krishnendu et al. (2012) present an integrated approach for selecting an appropriate supplier in the supply chain, addressing the carbon emissions issue, using fuzzy-AHP and fuzzy multi-objective linear programming. Liu et al. (2008) examine 500 companies for real-world decisions about where to outsource and summarize the current selection process by applying AHP. Recently, (Balfaqih et al., 2016) provide a review of the use of AHP models and other managerial methodologies to measure supply chain performance.

\subsubsection{GP}


GP is a distance-based multiple criteria decision making technique which provides solutions that are close as possible to a set of decision-maker specified goals. A comprehensive overview of the variants and techniques of GP is given by Jones and Tamiz, (2010). One of the significant recent variants is that of EGP (Romero, 2001; Romero, 2004), as it parametrically combines the notations of efficiency and balance found in the weighted and Chebyshev variants respectively. It is hence able to produce the weighted and Chebyshev goal program solutions via setting of the variant mix parameter at its extreme values. There is a significant range of fields of application of GP. Amongst those relevant to the case study presented in this paper, Alidrisi and Mohamed (2012) formulate a GP model in order to identify the extent to which each single strategy is inhibited by a lack of (or overloaded by) resources for supporting effective strategy in case study organizations. Jadid et al. (2014) propose a new multi-choice goal programming (MCGP) to solve a supplier selection problem, a multi-objective optimization problem with three minimization objectives: price, rejects and lead-time. The recent review of (Esmaeilikia et al., 2016) lists ten contributions to tactical supply chain planning based on the GP model.

\subsubsection{Combination of DEA, AHP and GP techniques}

The trend of combining and integrating GP with other techniques from within the field of Multiple Criteria Decision Making (MCDM) or wider Operational Research is identified and discussed by (Jones and Tamiz, 2010). This subsection considers the three combinations of two out the three techniques and the combination of all three techniques found in the literature. The concept of combining the AHP and GP techniques in order to enhanced decision making was first suggested by (Gass, 1986) in the context of military planning. (Jones and Tamiz, 2010) identify two main combinations of the two methods. The first, in the style of (Gass, 1986), is use the AHP to derive the criterion weights that can then be used in the GP achievement function in the weighted, Chebyshev or extended variants. The second is to use GP as a substitute for the Eigenvalue method when using the AHP. The first method will be that carried forward to the combination of DEA, AHP and GP developed in this paper. The concept of combining DEA and GP is discussed in (Jones and Tamiz, 2010), who draw upon the work of Cooper (2005) which identifies the similarities and differences between DEA and GP. Specifically, GP is seen as a planning technique whilst DEA is seen as a measurement and control technique. Therefore (Jones and Tamiz, 2010) recognize a worthwhile combination exists whereby DEA could be used to provide information about a set of units and subsequently GP could be used to select strategies to combat any inefficiencies identified by the DEA analysis. The third combination, that of DEA and AHP, can also be found in the literature. In a similar vein to the combination of DEA and GP, DEA could be used to provide information about a set of units and AHP used to prioritise or evaluate a set of potential actions. (Yadev and Sharma, 2015) is an example of this type of approach in the context of supplier selection. An alternative combination is to use AHP to determine some of the input or output scores in the DEA process, as demonstrated by (Lee et al., 2015) in the context of renewable energy planning. The former combination will be used in the combined DEA, AHP and GP methodology developed in this paper as the measurement associated with the DEA will need to take place before the AHP and GP are used to recommend a course of action.

Significantly less literature can be found that involves the combination of the three techniques of DEA, AHP and GP. (Kengpol et al., 2014) use DEA to assist an AHP-based risk analysis in the context of multimodal transportation route selection. They then perform a further AHP to assign relative weights to cost, time, risk and environmental criteria before solving a binary weighted GP model in order to select optimal routes. (Jablonsky, 2012) uses the AHP and GP separately to rank the efficiency of inefficient units from a DEA process and demonstrates the use of the resulting methods on a financial application. (Bae and Lee, 2011) use an imprecise DEA model to classify helicopter pilot risk in a military application. They then use a combination of AHP and GP in the sense of (Gass, 1986) to derive criteria weights and assign pilots to helicopters respectively.

\subsection{Summary of Gaps in the Literature}

Section 2.3 highlights the basis of the key issues and constraints impacting on the silk industry in Thailand. A set of priorities for action and investment options can be recommended to be the key issue in need of improvement. In addition, according to the mentioned case studies in the literature, there were recommendation points where the key constraints that caused concern are Product Problems, Inventory Management Problems, Management Problems, Marketing Problems, and Supply Chain Problems. 
Promsaka Na Sakolnakorn (2009) also presented that supply chain management and Inventory management were discovered to be key areas for improvement in the industry. Although the literature reveals interesting problems of coordination in the Thai silk's industry and different research areas, there is still no known research project in Thailand which truly studies in-depth regarding the current major problems and constraints in the industry. Graham (2011) also pointed out that there is no specific study on the production chains of the Thai silk industry at the time of writing. Thai silk producers are currently in a worrying economic position. The old global Multi-Fiber Arrangement (MFA), which expired in 2005, set export limits to wealthy countries on textiles (Yearman and Gluckman, 2005). However, since its expiration, there is a danger for Thai silk to become highly uncompetitive in comparison to Chinese and other imported fabrics. Contemporary logistics and supply chains are hence required for the expansion of the Thai silk industry (Thailand Textile Industry, 2009). Therefore, it becomes clear that having more applied research and knowledge transfer in supply chains will improve the industry. The studying of the literature also discovers that there is still no critical research in terms of supply chains and inventory management for the Thai Silk industry. The contributions of this paper will benefit Thailand's textile and silk industry. Thus, this paper will engage with the selected key constraints mentioned the literature. Supply Chain and Inventory Management will be the focal areas to be studied in the paper.

In terms of methodological gaps, it is noted that whilst there are natural synergies between the three techniques of DEA, AHP and GP, their combined usage in the context of supporting decision makers is rare. There are many potential orderings of the three techniques that have not been explored in practice. Specific to this paper, it is noted that there has not been a usage of DEA to provide a general assessment of the efficiency of a set of similar units followed by the formulation and solution of set of combined AHP and GP models designed to improve the shortcomings identified by the DEA process. Furthermore, newer GP variants such as EGP have not yet been incorporated into the combined process. These are methodological gaps that this paper seeks to address.

\section{Methodology}

The conducted research is both quantitative and qualitative in nature. Therefore, the research design and theoretical framework employs both quantitative and qualitative techniques. To obtain the desired information, a semi-structured interview, and an open and close-ended questionnaire are developed to enable key questions to be answered, such as companies' existing logistics strategies, and perceived major barriers. Data analysis techniques are employed for the interpretation of collected primary and secondary data. The research involves the aforementioned set of eight Thai silk manufacturers. Computer software LINGO version 14.0 and Microsoft Excel 2010 edition are used for optimization and data analysis.

\subsection{Research Structure}

The framework of the research procedures that are used in this study and the tasks of each stage are summarized and presented in Figure 3.

$\underline{\text { Decision Maker Information } \quad \text { Technique and Information Produced }}$ 


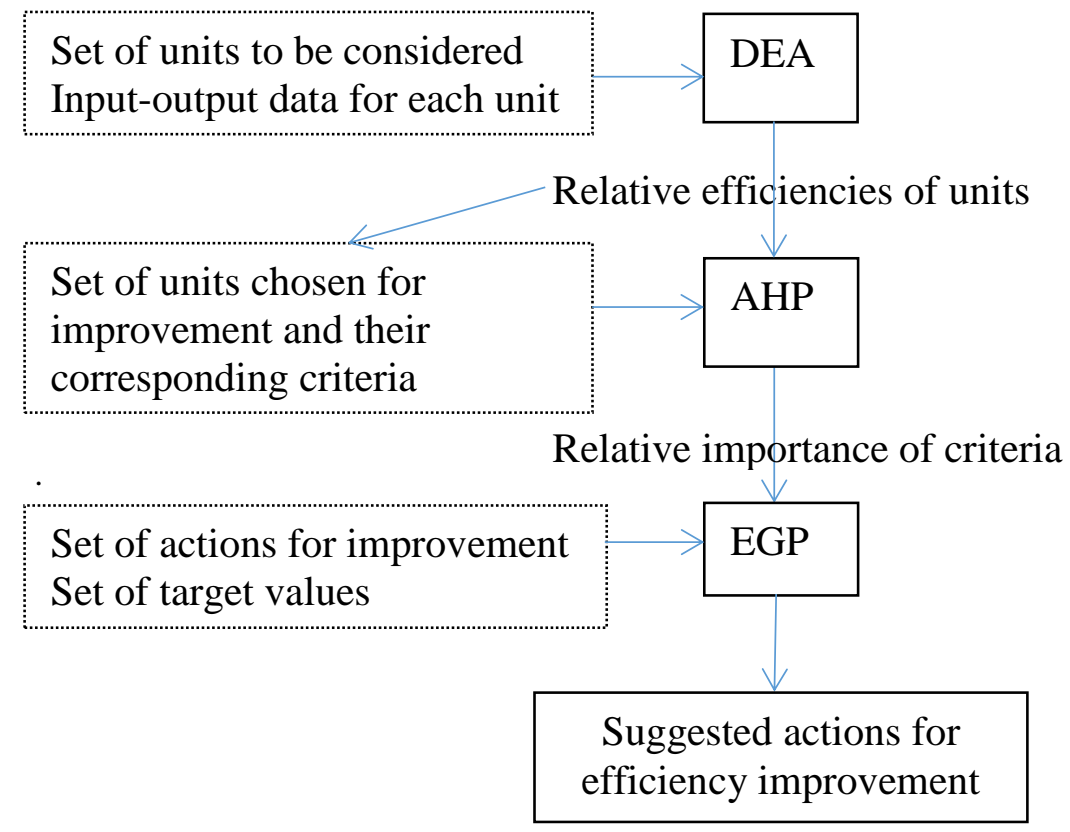

Fig 3 Methodology Framework

The methodology of combined usage of the DEA, AHP and EGP techniques is as follows. Firstly, a set of relevant units are identified and their inputs and outputs measures and associated data elicited from the decision maker(s). Information regarding the efficiency levels of the units is then used by the analyst to decide upon the nature of the strategic AHP/EGP models to be formulated. The relevant criteria and their relative importance are elicited from the decision maker(s) via the pairwise comparisons of the AHP technique. The standard processes of the AHP are also utilized in this process, such as inconsistency checking and resolution. The criteria importance levels from the AHP are then used as weights in the EGP model. The additional information required to build the EGP model, such the actions for improving the efficiency of individual units (decision variables) and the goal levels for each criteria are elicited form the decision maker at this point. A standard parametric or weight analysis on the EGP model can be carried out in order to provide distinct sets of potential improvements to the decision maker(s) in order to meet their specified goals. The above methodology is applied to the Thai Silk case study in this paper. The data collection methodologies are described in Section 3.2. The DEA models described in Section 5 pertain to the efficiency of suppliers and inventory processes. The AHP models described in Section 4 pertain to calculating criteria relevant to improvements to supplier and inventory processes, with necessary resolution of inconsistency and assessment of decision maker confidence included. The EGP models formulated in Section 6 calculate specific sets of inventory and supply chain improvement actions for three different EGP parameter settings.

\subsection{Data collection}

In this section, the company case selection is described. A brief overview of the interview guidelines and analysis is then presented. The case study literature review shows that two key focal areas manufacturers must consider in order to improve their efficiency are: Supply Chain and Inventory Management. Therefore, the preliminary variables can be classified into two main hierarchies, which include the decisions in supplier selections and inventory management, as shown by Table 1 . To obtain all variable sets for data analysis, a pilot expert interview was required. By having the supportive cooperation with Rajamangala University of Technology Thanyaburi (RMUTT) and The Queen Sirikit Department of Sericulture, there was a meeting being organised to interview the chairperson of a leading Thai silk company. The discussion topics were about some issues in supply chains, imports and exports, and computer software for inventory management. Factory tour and pilot expert interview were also achieved by cooperation from RMUTT to visit one of the 
well-known manufacturers. The discussion topics were about how they manage their large inventory and how are they dealing with multiple suppliers effectively.

\begin{tabular}{|c|c|c|}
\hline Main Criteria & Sub Criteria & Definition of the criteria \\
\hline \multirow{4}{*}{ Supplier Selection } & Product Quality & $\begin{array}{l}\text { The quality rating of the product or raw material } \\
\text { produced by the suppliers. }\end{array}$ \\
\hline & Service Level & $\begin{array}{l}\text { The performance rating that the manufactures feel for } \\
\text { their suppliers. }\end{array}$ \\
\hline & Management & $\begin{array}{l}\text { The management rating of how manufacturers feel for } \\
\text { their suppliers. }\end{array}$ \\
\hline & Financial Flow & $\begin{array}{l}\text { The flow rate in finances that manufacturers feel for their } \\
\text { suppliers. }\end{array}$ \\
\hline \multirow{5}{*}{$\begin{array}{l}\text { Decision in Inventory } \\
\text { Management }\end{array}$} & Inventory Cost & The total cost of inventory for one particular product. \\
\hline & Inventory Space & $\begin{array}{l}\text { The stocking space used for one particular order (in squre } \\
\text { metre). }\end{array}$ \\
\hline & Budget Constraint & The total budget for one particular order. \\
\hline & Delivery Time & On-time delivery rates to their customers. \\
\hline & Turnover rate & $\begin{array}{l}\text { The number of times inventory is sold or used in a time } \\
\text { period. }\end{array}$ \\
\hline
\end{tabular}

Table 1: The final variables of the Thai Silk Industry.

\begin{tabular}{cc}
\hline $\begin{array}{c}\text { Intensity of } \\
\text { Importance }\end{array}$ & Definition \\
\hline 1 & Equal importance. \\
\hline 2 & Weak or slight. \\
\hline 3 & Moderate importance. \\
\hline 4 & Moderate plus. \\
\hline 5 & Strong importance. \\
\hline 6 & Strong plus. \\
\hline 7 & $\begin{array}{c}\text { Very strong or } \\
\text { demonstrated } \\
\text { Importance. }\end{array}$ \\
\hline 9 & Very, very strong. \\
\hline
\end{tabular}

Table 2: The fundamental AHP scale

Table 1 represents the final variables collected from the expert interview. The main criteria are supplier selection and decision in inventory management. The sub-criteria of supplier selection consist of product quality, service level, management, and financial flow. The sub-criteria of decision in inventory management consist of inventory cost, inventory space, budget constraint, delivery time, and turnover rate. All definitions 
are given in table 1. After constructing an AHP hierarchy, a structured interview and data collection (AHP questionnaire) are applied in order to explore the weights analysis of each variable. This questionnaire is designed into two major sections. The first section was the qualitative questions where general information such as; company information, supply chains, logistic partners, inventory management, is requested. The second section concerns the AHP pair-wise comparisons. The measurements were made based on the standard AHP scale from 1 to 9, as shown by table 2. This data is further discussed in Section 4. Furthermore, input-output data is also collected in order to conduct the DEA analysis, after appropriate sets of inputs and output measures were agreed in consultation with the Thai silk companies involved. This data is given in Section 5. Finally, after the results of the first two analyses (DEA and AHP) were known, the set of improvement actions and goal targets for the EGP model were agreed from further meetings with the Thai silk companies. Additionally, the technological coefficients of the EGP (i.e. the estimated difficulty levels of each proposed action) were agreed upon by the companies. The corresponding data is given in Section 6.

\section{Decision Making Analysis using the Analytic Hierarchy Process (AHP)}

The AHP method is used to elicit the relative importance of the problem criteria to the decision maker. The AHP has been chosen for this purpose because of its established track record in AHP and GP integration, dated back to the seminal work of (Gass, 1986). This section presents the findings, analysis, and results of the AHP questionnaire. The main characteristic of the AHP is that it is based on pairwise comparison judgments. The operational process is illustrated in Figure 4. Firstly, all necessary variables must be identified. Secondly, a questionnaire based on AHP method is developed. Key decision maker answers are given on the 1-9 rating shown by Table 2. Thirdly, set of weights from the answers of the key decision makers is obtained. Fourthly, a consistency examination must be undertaken in order to measure a reliability of the data obtained from the questionnaire collection and appropriate rectification action taken in the case of excessive inconsistency (Lin Lai, 2013).

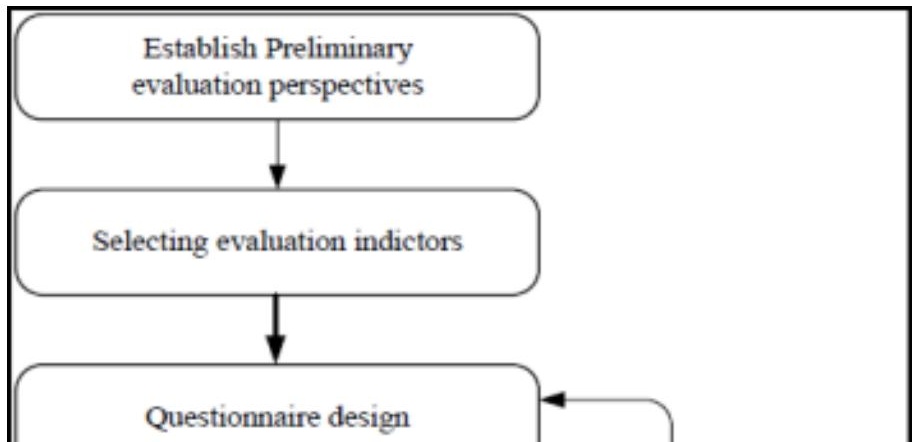


Fig 4 The AHP operational process

To check for consistency, Saaty (1990) proposed the Consistency ratio (CR), which is the ratio between Consistency Index (CI) and Random Consistency Index (RI). If the value of Consistency Ratio is smaller or equal to $0.1(10 \%)$, the inconsistency is acceptable. If the Consistency Ratio is greater than $10 \%$, it need to consider revising subjective judgments; otherwise, the questionnaire has to be returned for re-answering or resolved by a numerical method that improves the reliability of the weight. The results will be shown by highlighting "Silk Manufacturer 1", one of the leading Thai silk manufacturers located in the northern part of Thailand. The name is withheld for reasons of confidentially. The first section of the result will address the AHP being applied in supplier selection of the case study. The second section presents the AHP being applied with inventory management of the case study.

\subsection{Supplier Selection Analysis}

\begin{tabular}{|c|c|c|c|c|c|c|c|}
\hline \multirow{2}{*}{ Decision Variables } & \multicolumn{4}{|c|}{ Original Rating } & \multirow{2}{*}{ Weights } & \multirow{2}{*}{ C.I. } & \multirow{2}{*}{ C.R. } \\
\hline & P.Q & S.L. & $M$ & F.F. & & & \\
\hline Product Quality & 1 & 1 & 4 & 4 & 0.37 & \multirow{4}{*}{0.12} & \multirow{4}{*}{0.13} \\
\hline Service Level & 1 & 1 & 5 & 5 & 0.42 & & \\
\hline Management & 0.25 & 0.2 & 1 & 5 & 0.15 & & \\
\hline Financial Flow & 0.25 & 0.2 & 0.2 & 1 & 0.06 & & \\
\hline
\end{tabular}


Table 3: The Results of Supplier Selection for Silk Manufacturer 1

\subsection{Decision in Inventory Management Analysis}

\begin{tabular}{|c|c|c|c|c|c|c|c|c|}
\hline \multirow{2}{*}{ Decision Variables } & \multicolumn{5}{|c|}{ Original Rating } & \multirow{2}{*}{ Weights } & \multirow{2}{*}{ C.I. } & \multirow{2}{*}{ C.R. } \\
\hline & I.C. & I.S. & B.C. & D.T. & T.R. & & & \\
\hline Inventory Cost & 1 & 4 & 1 & 0.33333 & 0.25 & 0.17 & \multirow{5}{*}{0.24} & \multirow{5}{*}{0.22} \\
\hline Inventory Space & 0.25 & 1 & 1 & 1 & 0.33333 & 0.11 & & \\
\hline Budget Constraint & 1 & 1 & 1 & 3 & 1 & 0.23 & & \\
\hline Delivery Time & 3 & 1 & 0.33333 & 1 & 1 & 0.20 & & \\
\hline Turnover rate & 4 & 3 & 1 & 1 & 1 & 0.29 & & \\
\hline
\end{tabular}

Table 4: The Results of Decision in Inventory Management for Silk Manufacturer 1

Considering the data presented in terms of supplier selection, $\mathrm{CI}=0.12$ and $\mathrm{CR}=0.13$, they are both higher than 0.1. Among these decision variables, "Service Level" is found to be the most important variable (0.42). In terms of decision in inventory management, $\mathrm{CI}=0.24$ and $\mathrm{CR}=0.22$, they were both considerably higher than 0.1 , and "Turnover rate" is found to be the most important variable (0.29). AHP provides quantitative weights to be used in decision support. It does not, however, include statistical assessment of the uncertainty of the results. Mikko et al. (2000) suggested a variance components modeling approach, where uncertainty or variation of the judgments in the case of multiple judges can be divided into three parts: (1) interpersonal variation around the population mean; (2) possible shared logical inconsistency of the judgments among the judges; and (3) residual uncertainty.

In order to measure how confident the key decision makers are in answering the questions of the AHP survey, there is one additional question asking them to answer regarding the level of confidence. A rating scale method is selected. The scale is set as the follows 1 (not confident), 3 (low), 5 (medium confidence), 7 (high), and 9 (totally confident). The results are summarized as shown in Table 5 and Figure 5.

\begin{tabular}{|c|c|c|c|}
\hline \multirow[b]{2}{*}{ Manufactures } & \multirow{2}{*}{$\begin{array}{c}\text { Confidence } \\
\text { Levels }\end{array}$} & \multicolumn{2}{|c|}{ Consistency Ratio } \\
\hline & & $\begin{array}{l}\text { Supplier } \\
\text { Selection }\end{array}$ & $\begin{array}{c}\text { Inventory } \\
\text { Management }\end{array}$ \\
\hline Silk Manufacturer 1 & 7 & 0.13 & 0.22 \\
\hline Silk Manufacturer 2 & 7 & 0.24 & 0.04 \\
\hline Silk Manufacturer 3 & 9 & 0.49 & 0.34 \\
\hline Silk Manufacturer 4 & 5 & 0.54 & 0.48 \\
\hline Silk Manufacturer 5 & 7 & 0.28 & 0.23 \\
\hline Silk Manufacturer 6 & 5 & 0.41 & 1.04 \\
\hline Silk Manufacturer 7 & 9 & 0.22 & 0.37 \\
\hline Silk Manufacturer 8 & 7 & 0.44 & 0.50 \\
\hline
\end{tabular}

Table 5: Confidence levels against consistency ratio

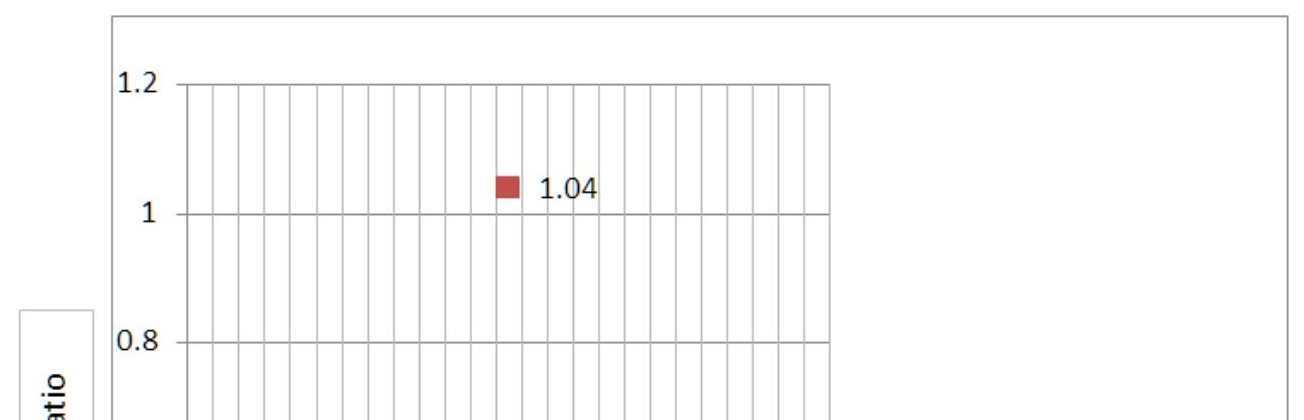


Fig 5 Graphical summary of confidence levels against consistency ratio

As previously mentioned, if the Consistency Index (CI) and Consistency Ratio (CR) are higher than 0.1 $(10 \%)$, the questionnaire has to be returned for re-answering or, if this is however not feasible, resolved by other means such as algorithmic method for dealing with inconsistencies in pairwise comparisons, which improves the reliability of the results. According to figure 5, it is discovered that the confidence feedbacks of the questionnaire respondents are medium to high, while the inconsistencies still existed. From the authors' point of view, the respondents are familiar with the processes of their company and industry, resulting in the medium-high level of confidence expressed. However, they appear to be less familiar with the use of pairwise comparisons of AHP methodology, resulting in the relatively high levels of inconsistency. Therefore in order to reduce the inconsistency level, rather than retuning the questionnaire to the key decision makers for reanswering, an automated algorithm is selected instead. This is because the authors avoids to point inconsistencies out to decision makers and are not confident that a re-answering will lead to an acceptable level of inconsistency. Therefore a numerical method was chosen that searches for consistency whilst differing from the original responses "as little as possible". The selected method was introduced by Gonzalez and Romero (2003). The paper proposed GP as an attractive and flexible tool for a distance-based framework for analyzing this kind of compatibility to solve inconsistencies in pairwise comparisons. The main idea of the proposed GP model is how to modify, with at least changes as possible, the information contained in inconsistent PC matrix in order to approximate it, as closely as possible, to a reciprocal and consistent modified matrix. The Gonzalez and Romero (2003) method is modified to enforce reciprocracy as non-reciprocal matrices are complex to analyze in practice. These leads to the revised algebraic model for a sample AHP matrix of size four $(A)$ presented in model (2)- (6). The model presented has also been modified from Gonzalez and Romero's model in order to force the resulting weight matrix to maintain reciprocity, achieved by equation set (4) which has been modified from goal to hard constraint format. Achievement function (2) minimizes the sum of deviations from the similarity goals and consistency goals. Single

parameter $\mathrm{u}$ gives the balance between the relative importance of similarity and consistency in the achievement function. Goal set (3) aims to achieve the similarity condition compared to the original matrix. Goal set (5) aims to improve consistency of the matrix. Constraint set (6) ensures the range of each decision variable is kept within the AHP scale.

$A=\left[\begin{array}{llll}1.00 & 5.00 & 0.50 & 3.00 \\ 0.20 & 1.00 & 3.00 & 0.33 \\ 2.00 & 0.33 & 1.00 & 0.50 \\ 0.33 & 3.00 & 2.00 & 1.00\end{array}\right]$ 
Achievement function:

Min $\mathrm{a}=\mathrm{u} \sum_{i=1}^{12}\left(n_{i}^{(1)}+p_{i}^{(1)}\right)+\sum_{t=1}^{24}\left(n_{t}^{(3)}+p_{t}^{(3)}\right)$

Subject to:

$$
\begin{aligned}
& w_{12}+n_{1}^{(1)}-p_{1}^{(1)}=5, \quad w_{13}+n_{2}^{(1)}-p_{2}^{(1)}=0.5, \quad w_{14}+n_{3}^{(1)}-p_{3}^{(1)}=3, \\
& w_{21}+n_{4}^{(1)}-p_{4}^{(1)}=0.2, \quad w_{23}+n_{5}^{(1)}-p_{5}^{(1)}=3, \quad w_{24}+n_{6}^{(1)}-p_{6}^{(1)}=0.33, \\
& w_{31}+n_{7}^{(1)}-p_{7}^{(1)}=2.0, \quad w_{32}+n_{8}^{(1)}-p_{8}^{(1)}=0.33, w_{34}+n_{9}^{(1)}-p_{9}^{(1)}=0.5, \\
& w_{41}+n_{10}^{(1)}-p_{10}^{(1)}=0.33, \quad w_{42}+n_{11}^{(1)}-p_{11}^{(1)}=3, \quad w_{43}+n_{12}^{(1)}-p_{12}^{(1)}=2 ; \\
& w_{12} w_{21}=1, w_{13} w_{31}=1, w_{14} w_{41}=1, \\
& w_{23} w_{32}=1, w_{24} w_{42}=1, w_{34} w_{43}=1 ; \\
& w_{13} w_{32}-w_{12}+n_{1}^{(3)}-p_{1}^{(3)}=0, \quad w_{13} w_{32}-w_{12}+n_{1}^{(3)}-p_{1}^{(3)}=0, \\
& w_{12} w_{23}-w_{13}+n_{3}^{(3)}-p_{3}^{(3)}=0, \quad w_{14} w_{43}-w_{13}+n_{4}^{(3)}-p_{4}^{(3)}=0 \text {, } \\
& w_{12} w_{24}-w_{14}+n_{5}^{(3)}-p_{5}^{(3)}=0, \quad w_{13} w_{34}-w_{14}+n_{6}^{(3)}-p_{6}^{(3)}=0, \\
& w_{23} w_{31}-w_{21}+n_{7}^{(3)}-p_{7}^{(3)}=0, \quad w_{24} w_{41}-w_{21}+n_{8}^{(3)}-p_{8}^{(3)}=0, \\
& w_{21} w_{13}-w_{23}+n_{9}^{(3)}-p_{9}^{(3)}=0, \quad w_{24} w_{43}-w_{23}+n_{10}^{(3)}-p_{10}^{(3)}=0, \\
& w_{21} w_{14}-w_{24}+n_{11}^{(3)}-p_{11}^{(3)}=0, \quad w_{23} w_{34}-w_{24}+n_{12}^{(3)}-p_{12}^{(3)}=0, \\
& w_{32} w_{21}-w_{31}+n_{13}^{(3)}-p_{13}^{(3)}=0, \quad w_{34} w_{41}-w_{31}+n_{14}^{(3)}-p_{14}^{(3)}=0, \\
& w_{31} w_{12}-w_{32}+n_{15}^{(3)}-p_{15}^{(3)}=0, \quad w_{34} w_{42}-w_{32}+n_{16}^{(3)}-p_{16}^{(3)}=0, \\
& w_{31} w_{14}-w_{34}+n_{17}^{(3)}-p_{17}^{(3)}=0, \quad w_{32} w_{24}-w_{34}+n_{18}^{(3)}-p_{18}^{(3)}=0, \\
& w_{42} w_{21}-w_{41}+n_{19}^{(3)}-p_{19}^{(3)}=0, \quad w_{43} w_{31}-w_{41}+n_{20}^{(3)}-p_{20}^{(3)}=0, \\
& w_{41} w_{12}-w_{42}+n_{21}^{(3)}-p_{21}^{(3)}=0, \quad w_{43} w_{32}-w_{42}+n_{22}^{(3)}-p_{22}^{(3)}=0, \\
& w_{41} w_{13}-w_{43}+n_{23}^{(3)}-p_{23}^{(3)}=0, \quad w_{42} w_{23}-w_{43}+n_{24}^{(3)}-p_{24}^{(3)}=0 ; \\
& 0.11 \leq w_{i j} \leq 9 \quad i=1, \ldots, 3 ; \quad j=1, \ldots, 4
\end{aligned}
$$


Where $w_{i j}$ indicates the entry for row $i$ and column $j$ of the revised AHP matrix. $n_{k}^{(1)}$ and $p_{k}^{(1)}$ are the negative and positive deviations from the similarity goal of the $k^{\prime}$ th element of the AHP matrix (assuming a row before column ascending ordering of matrix elements) respectively. $n_{l}^{(3)}$ and $p_{l}^{(3)}$ are the negative and positive deviations from the $l^{\prime}$ th consistency goal, following the assumed order of goals in (5). The superscript ${ }^{(2)}$ is intentionally not used for deviation variable sets in order to maintain consistency with the Gonzalez and Romero (2003) formulation. The model (2)-(6) has the advantages of a more simple sensitivity analysis (due to only one parameter) and is easier to process through standard means (as it is still reciprocal). This is at the disadvantage of the loss of some modelling flexibility due to the tighter constraints imposed by (3).

After solving the models, the consistency values for all eight companies became less than $10 \%$, which means the adjusted consistency (shown in Table 6) is now considered to be acceptable for further analysis.

\begin{tabular}{|l|c|c|l|c|c|}
\hline \multicolumn{3}{|c|}{ Supplier Selection of Silk Manufacturer 1 } & \multicolumn{2}{c|}{ Decision in Inventory Management of Silk Manufacturer 1 } \\
\hline & Original weights & Adjusted weights & & Original weights & Adjusted weights \\
\hline Product Quality & 0.37 & 0.36 & Inventory Cost & 0.17 & 0.12 \\
\hline Service Level & 0.42 & 0.45 & Inventory Space & 0.11 & 0.15 \\
\hline Management & 0.15 & 0.15 & Budget Constraint & 0.23 & 0.20 \\
\hline Financial Flow & 0.06 & 0.06 & Delivery Time & 0.20 & 0.21 \\
\hline & & & Turnover rate & 0.29 & 0.32 \\
\hline \multicolumn{1}{|c|}{ CR } & $\mathbf{0 . 1 3}$ & $\mathbf{0}$ & CR & $\mathbf{0 . 2 2}$ & $\mathbf{0 . 0 6 3}$ \\
\hline
\end{tabular}

Table 6: The summary table of the adjusted consistency ratios

\section{Efficiency Analysis using DEA}

This section presents the method of using DEA for measuring the efficiency of the companies' existing suppliers and inventory departments. The data set is acquired from the statistical data of the manufacturers regarding their existing suppliers and recent sample orders kept in the inventories. The existing suppliers of each of the manufacturers is measured regarding their performances based on the part of the questionnaire which is specifically developed for the DEA analysis. The recent sample orders in each of manufacturers are measured regarding their recorded inventory data to find out the actual efficiency level. This analysis provides key decision makers a clear vision to find out where are the problems to pay more attention when considering to their suppliers and the past inventory activities.

\subsection{The Orientation of the DEA Analysis}

There are two basic orientations, which are input and output. An input orientation focuses on the proportional decrease of the input vector while the output orientation adjusts the proportional increase of the output (Martin and Roman 2001). The selected inputs and outputs for data analysis can be seen in Tables 7 and 8 .

\begin{tabular}{|c|c|}
\hline Inputs & Outputs \\
\hline Average Cost per Unit & Product Quality \\
\hline Labours & Service Level \\
\hline Vehicles & Management \\
\hline & Financial Flow \\
\hline
\end{tabular}


Table 7: Inputs and Outputs for supplier analysis.

\begin{tabular}{|l|l|}
\hline \multicolumn{1}{|c|}{ Inputs } & \multicolumn{1}{c|}{ Outputs } \\
\hline SKUs (Stock Keeping Units) & Inventory Cost (Total Inventory cost of the order) \\
\hline Inventory Space (Squre Metre for stocking) & Delivery Time (On time percentage Rating) \\
\hline Budget (Annual Budet per order per year) & Turnover Rate (Annual Turnover) \\
\hline Labours & \\
\hline
\end{tabular}

Table 8: Inputs and Outputs for inventory management analysis.

Table 7 represents the sets of inputs and outputs for suppliers' efficiency analysis. According to the pilot interviews in Thailand regarding supplier selection perspectives, there are three inputs that are commonly considered for an investment. The inputs consist of the average cost per unit, labor (the number of people used for dealing with specific supplier), and vehicles (a number of vehicles used for transportation). Table 8 represents the sets of inputs and outputs for inventory efficiency analysis. The inputs consist of stock keeping units, space, budget, and labor. The outputs are as follows; inventory cost, delivery time, and turnover. Regarding "Inventory Cost", manufacturers in the industry have been working hard in order to reduce it to a low level. In order to use the standard DEA form, all "Inventory Cost" data in the experiments are changed into maximization "more is better" format by a simple mathematical transformation. The delivery time in the analysis is measured by percentage rating output. It is important since just-in-time delivery has become increasingly commonplace and customer demands continue to tighten, the importance of fast, reliable delivery performance cannot be overstated (Milgate, 2001). The turnover rate represents the inventory turnover ratio that shows how effectively inventory is managed by comparing cost of goods sold with average inventory for a period. This measures how many times average inventory is turned or sold during a period.

\subsection{Efficiency Analysis}

According to the information from the highlighted case study "Silk Manufacturer 1", there are five of their existing suppliers that the manufacturer provided for an analysis. The list of the suppliers are set as: Supplier No.1-5 for reasons of confidentiality. The data sets of inputs and outputs for each of the suppliers are given as seen in Table 8. In order to generate numerical data for the outputs, a 1-5 rating scale method is undertaken. Combining words and numbers in a 1-to-5 rating scale provides an effective yet simple method for measuring the relative performance or importance of personal and business options. Therefore, in terms of suppliers' performance analysis, the decision makers are required to rate those outputs by using 1-5 rating scales. In terms of inventory analysis, there are five recent orders that the manufacturer provides for an analysis. The sample orders consists Convertible neck, Boat neck-1, Mandarin neck, Shawl neck, and Round neck-1. The sets of inputs and outputs for each of the orders are

given in Table 9.

\begin{tabular}{|c|c|c|c|c|c|c|c|}
\hline \multirow[b]{2}{*}{ Suppliers } & \multicolumn{3}{|c|}{ Inputs } & \multicolumn{4}{|c|}{ Outputs } \\
\hline & Average Cost per Unit & Labours & Vehicles & Product Quality & Service Level & Management & Financial Flow \\
\hline Supplier 1 & 1300 & 8 & 5 & 4 & 3 & 3 & 4 \\
\hline Supplier 2 & 1400 & 10 & 7 & 4 & 3 & 3 & 2 \\
\hline Supplier 3 & 1050 & 8 & 8 & 4 & 3 & 2 & 4 \\
\hline Supplier 4 & 950 & 5 & 3 & 4 & 5 & 4 & 5 \\
\hline Supplier 5 & 1200 & 7 & 5 & 4 & 2 & 4 & 3 \\
\hline
\end{tabular}


Table 9: Inputs and outputs for suppliers' efficiency analysis.

\begin{tabular}{|c|c|c|c|c|c|c|c|c|}
\hline & & \multicolumn{4}{|c|}{ Inputs } & \multicolumn{3}{|c|}{ Outputs } \\
\hline & Style & SKUs & Inventory Space & Budget & Labours & Inventory Cost & Delivery Time & Turnover Rate \\
\hline Sample Order 1 & Convertible neck & 784 & 10 & 980000 & 10 & 10092 & 100 & 0.51 \\
\hline Sample Order 2 & Boat neck-1 & 392 & 5 & 490000 & 7 & 14796 & 100 & 0.71 \\
\hline Sample Order 3 & Mandarin neck & 784 & 9 & 980000 & 7 & 10092 & 100 & 0.65 \\
\hline Sample Order 4 & Shawl neck & 784 & 10 & 980000 & 7 & 10092 & 100 & 0.77 \\
\hline Sample Order 5 & Round neck-1 & 1176 & 15 & 1470000 & 15 & 5388 & 100 & 0.82 \\
\hline
\end{tabular}

Table 10: Inputs and outputs for inventory's efficiency analysis.

\begin{tabular}{|l|c|}
\hline \multicolumn{1}{|c|}{ Silk Manufacturer 1 } & \multirow{2}{*}{ DEA Scores } \\
\cline { 1 - 1 } & \\
\hline Supplier 1 & $\mathbf{0 . 7 3}$ \\
\hline Supplier 2 & $\mathbf{0 . 6 7}$ \\
\hline Supplier 3 & $\mathbf{0 . 9}$ \\
\hline Supplier 4 & $\mathbf{1}$ \\
\hline Supplier 5 & $\mathbf{0 . 7 9}$ \\
\hline \multicolumn{2}{|c|}{} \\
\hline
\end{tabular}

Table 11: DEA scores of suppliers analysis.

\begin{tabular}{|l|l|c|}
\hline \multicolumn{2}{|c|}{ Silk Manufacturer 1 } & DEA Scores \\
\multicolumn{2}{|l|}{} & \\
\hline Sample Order 1 & Convertible neck & $\mathbf{0 . 7}$ \\
\hline Sample Order 2 & Boat neck-1 & $\mathbf{1}$ \\
\hline Sample Order 3 & Mandarin neck & $\mathbf{1}$ \\
\hline Sample Order 4 & Shawl neck & $\mathbf{1}$ \\
\hline Sample Order 5 & Round neck-1 & $\mathbf{0 . 5 2}$ \\
\hline
\end{tabular}

Table 12: DEA scores of inventory analysis

Considering the results of the suppliers' analysis, "Supplier 4" obtained 100 percent which indicates it is the best supplier from those considered. The minimal score received was "Supplier 2" (67 percent). The results from inventory analysis reveal that "Convertible neck" got 70 percent and "Round neck-1" got 52 percent, which mean two out of five items are less efficient than the others. The manufacturer might also focus their attention on improving these inefficient categories. According to the experiences of this experiment, the efficiency scores of suppliers and inventories have been revealed that there are inefficient aspects of the supply chain to be considered. Song (2013) pointed out that there are many sources of uncertainties in a supply chain. The three most important categories of uncertainties are as follows: 1) supply uncertainty such as material supply or subcontract order, 2) manufacturing uncertainty such as processing time and resource availability, and 3) customer uncertainty such as customer orders or demand arrivals. The third category is 
an external uncertainty, which is caused by unpredictable market environments and customer requirement changes. In terms of the scope of this research, it is discovered that there are supplier performance issues, however those issues are considered to be an external uncertainty, which is out of the scope. The manufacturers must take their own consideration whether or not they should keep conducting business with those less well performing suppliers. Therefore, in terms of further prescriptive analytics, the research principally engages with inventory management, which is discussed in the next section.

\section{Use of GP to suggest Strategic Enhancements to Supply Chain Practices}

This section discusses the method of using GP models for the optimal inventory management strategies. GP is one of the most widely used techniques for MCDM. Schniederjans (1995) gives a large number of pre1995 articles relating to GP. A recent textbook by Jones and Tamiz (2010) gives a comprehensive overview of GP. This technique can be thought of as an extension or generalization of linear programming to handle multiple, normally conflicting objective measures. Each of these measures is given a goal or target value to be achieved. Unwanted deviations from this set of target values are then minimized in an achievement function. This can be a vector or a weighted sum dependent on the GP variant used. As satisfaction of the target is deemed to satisfy the decision maker(s), an underlying satisficing philosophy is assumed.

\subsection{Formulation of an EGP Model}

An EGP model is built in this section, specifically focused on an analysis of inventory optimization. In terms of this optimization, the goals used in GP models are set the same as decision variables seen in the AHP analysis section which consists of inventory cost, inventory space, budget, delivery time, and turnover. The analysis is composed of the following activities:

A. Identify the objective (e.g., the objective is to optimize all given variables in an inventory analysis).

B. From the objective in (A), determine the specific goals to be achieved.

C. Use the AHP result to determine the weights for the goals identified in (B).

D. Using the information in (C), develop the EGP model and solve it with different values of the variant mix parameter to obtain a small set of potential solutions for the Thai silk manufacturing managers to consider.

Once the choice of GP analysis has been made, an orientation of the model to implement models analysis is needed. There are four basic orientations, which include specific goals to be achieved, set of actions to achieve the goals, contribution sets between actions and goals, and difficulty level required to implement those actions. In terms of an inventory optimization, the ultimate purpose of inventory management is optimization of the inventory policy for the whole production-distribution system to minimise total operating inventory costs while maximizing profits and maintaining a high level of customer service (Hamontree, 2014). This means that the objective of optimal inventory control is to make a balance between the conflicting goals. Cavinato and Kauffman (2000) present nine actions that can be considered when thinking of inventory improvement, as illustrated by the first column of table 13 .

Inventory is a major source of cost in the supply chain and it has a huge impact on responsiveness (Chopra and Meindl, 2007). An important role that inventory plays in the supply chain is to increase the amount of demand that can be satisfied by having a product ready and available when the customer wants to use it. Another significant role is to reduce costs by utilizing any economies of scale that may exist during both production and distribution. Table 13 also represents the goals that will be contributed by those actions. The company manager determines the target values of the goals.

Considering table 13, there are 45 sets of contributions in total ( 9 actions for 5 goals). Key decision makers provide this required information in order to obtain the actual values of contribution sets. In order to be convenient for the interviewee to answer those conflicting questions, a percentage approach is applied (e.g. how many percent do you think that Action 1 could improve Goal 1?). After that, the contribution values are generated based on the average value of each goal. The target values of the goals were also indicated according to the key decision maker's preference. After contribution values were received, decision makers then answer how they feel in term of difficulty levels for implementing those actions. Table 14 represents the 
table of data collection regarding the difficulty levels of the actions answered by key decision makers. There are five levels as follows; easy, normal, hard, very hard, and intense. Those levels are given specific values as; $1,2,5,8$, and 10 respectively. The above considerations lead to the following EGP model formulation:

$$
\operatorname{MIN} \mathrm{a}=\alpha \lambda+(1-\alpha)\left[\sum_{k=1}^{5}\left(\frac{u_{k} n_{k}}{b_{k}}+\frac{v_{k} p_{k}}{b_{k}}\right)+\frac{P_{d}}{D}\right]
$$

Subject to

$$
\begin{array}{ll}
\sum_{i=1}^{9} e_{i k} x_{i}+n_{k}-p_{k}=b_{k} & k=1, \ldots, 5 \\
\sum_{i=1}^{9} d_{i} x_{i}+n_{d}-p_{d}=D & \\
\frac{u_{k} n_{k}}{b_{k}}+\frac{v_{k} p_{k}}{b_{k}} \leq \lambda & k=1, \ldots, 5 \\
\frac{P_{d}}{D} \leq \lambda & \\
x_{i}=0 \text { or } 1 & i=1, \ldots, 9 \\
n_{k}, p_{k} \geq 0 k=1, \ldots, 5 ; \lambda \geq 0 &
\end{array}
$$

Where:

$$
\begin{array}{ll}
x_{i} & \text { is the decision variable representing whether action } i \text { is undertaken or not } \\
p_{d} & \text { is the positive deviation from the target difficulty level } D . \\
n_{d} & \text { is the negative deviation from the target difficulty level } D . \\
b_{k} & \text { is a target value for goal } k, \\
n_{k} & \text { is the negative deviation from }\left(b_{k}\right) \\
p_{k} & \text { is the positive deviation from }\left(b_{k}\right) \\
u_{k} & \text { is the negative deviation weight (from the AHP analysis). } \\
v_{k} & \text { is the positive deviation weight (from the AHP analysis). } \\
e_{i k} & \text { is the contribution of action } i \text { towards goal } k . \\
d_{i} & \text { is the level of difficulty of implementing action } i . \\
D & \text { is a maximum difficulty goal level for all the chosen actions. } \\
\lambda & \text { is the maximum normalized, weighted, unwanted deviation }
\end{array}
$$

Achievement function (7) minimizes the unwanted deviations according to the EGP philosophy. The parameter $\alpha$ controls the mix between minimizing the worst case deviation (balance) and minimizing the sum of deviations (efficiency). Note that if the deviation is not unwanted, then its corresponding weight $u_{k}$ or $v_{k}$ is set equal to zero. Goal set (8) gives the deviations from the desired target value for the five goals under consideration. Goal (9) gives the deviation from the desired maximum level of total difficulty. Constraint set (10) and constraint (11) determine the maximum weighted, normalized unwanted deviation from the set of goals given by (8) and (9). Sign restriction set (12) ensures that all the action variables $x_{i}$ are binary. Sign restriction set (13) ensure all the deviational variables, including the maximum deviation, are non-negative. Model (7)-(13) is solved for all eight Thai silk manufacturers using the LINGO software, version 14.0 for three zeros of parameter $\alpha$. These are $\alpha=0$, representing the weighted GP solution and 
hereafter referred to as the "weighted GP" solution ; $\alpha=0.5$, representing a mix between efficiency and balance and hereafter referred to as "Extended GP" solution; and $\alpha=1$, A representing Chebyshev GP and hereafter referred to as the "Chebyshev GP" solution. As a representative example, silk manufacturer 1 is discussed in Section 6.2 below.

\subsection{The Data and Results for Silk Manufacturer 1.}

Table 13 represents the sets of contributions answered by Silk Manufacturer 1's manager. Table 14 represents the difficulty levels of implementing the actions.

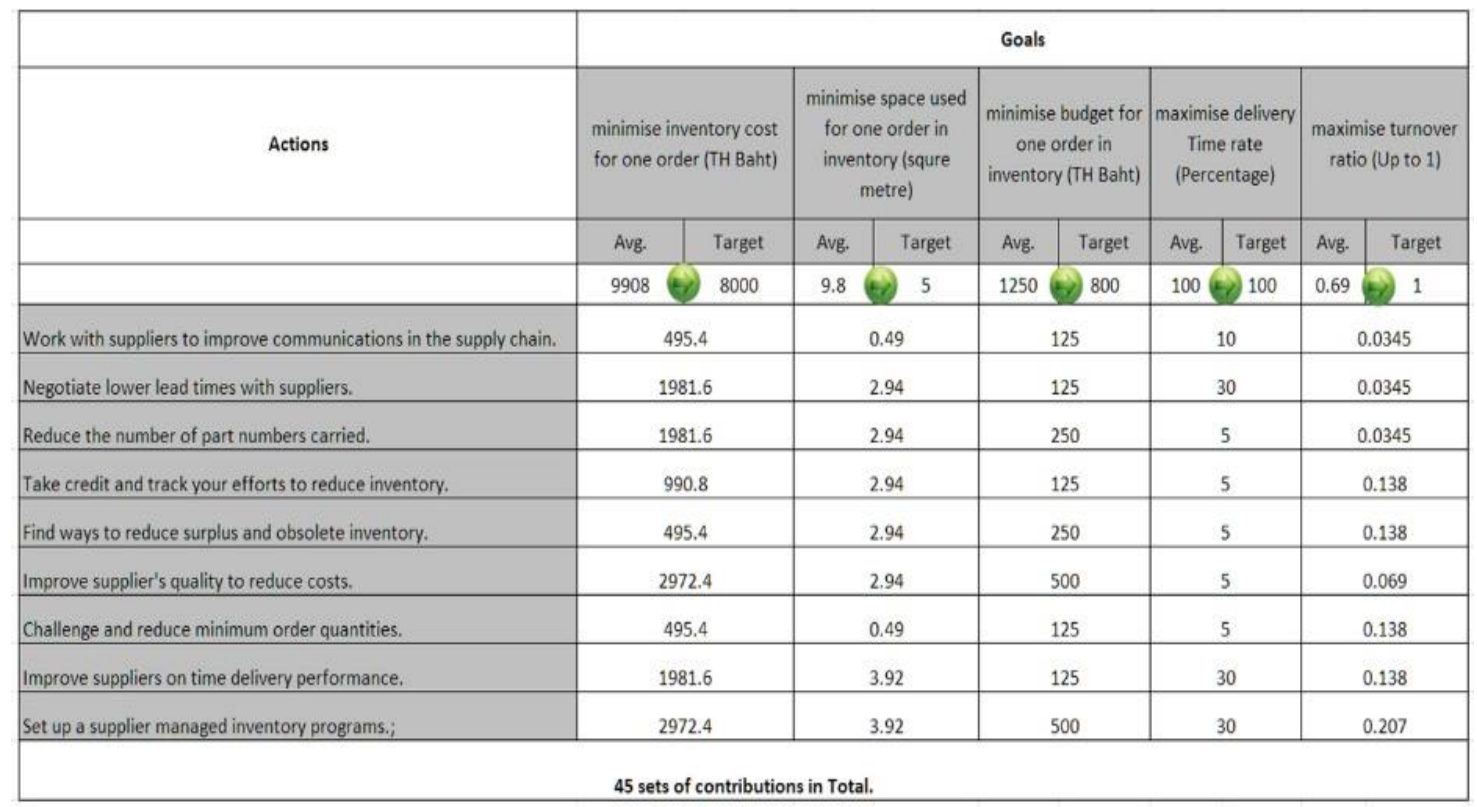

Table 13: GP Data collection of Silk Manufacturer 1.

\begin{tabular}{|c|l|l|l|l|l|l|}
\hline \multicolumn{2}{|c|}{ Actions } & \multicolumn{3}{c|}{ Difficulty Levels } \\
\cline { 5 - 6 } \multicolumn{2}{|c|}{} & Easy & Normal & Hard & Very Hard & Intense \\
\hline $\mathrm{X} 1$ & Work with suppliers to improve communications in the supply chain. & & & & & \\
\hline $\mathrm{X} 2$ & Negotiate lower lead times with suppliers. & & & & & \\
\hline $\mathrm{X} 3$ & Reduce the number of part numbers carried. & & & & & \\
\hline $\mathrm{X} 4$ & Take credit and track your efforts to reduce inventory. & & & & & \\
\hline $\mathrm{X} 5$ & Find ways to reduce surplus and obsolete inventory. & & & & & \\
\hline $\mathrm{X} 6$ & Improve supplier's quality to reduce costs. & & & & & \\
\hline $\mathrm{X} 7$ & Challenge and reduce minimum order quantities. & & & & & \\
\hline
\end{tabular}


Table 14: Difficulty levels of the actions.

\section{Actions}

$\mathrm{X}(1)$

$\mathrm{X}(2)$

$x(3)$

$X(4)$

$\mathrm{X}(5)$

$\mathrm{x}(6)$

$\mathrm{X}(7)$

$X(8)$

$\mathrm{X}(9)$

Weighted

\section{Actions}

0.000000
0.000000
1.000000
1.000000
0.000000
0.000000
0.000000
1.000000
0.000000
$\mathrm{X}(1)$
$\mathrm{X}(2)$
$\mathrm{X}(3)$
$\mathrm{X}(4)$
$x(5)$
$x(6)$
$\mathrm{X}(7)$
$\mathrm{X}(8)$
$\mathrm{X}(9)$

Extended (equal mix)

\section{Actions}

$\begin{array}{ll}1.000000 & x(1) \\ 0.000000 & x(2) \\ 0.000000 & x(3) \\ 1.000000 & x(4) \\ 1.000000 & x(5) \\ 0.000000 & x(6) \\ 1.0000000 & x(7) \\ 0.000000 & x(8) \\ 0.000000 & x(9)\end{array}$

$1.000000 \varnothing$

0.000000

0.000000

0.000000

1.000000

0.000000

0.000000

1.000000

0.000000

Fig 6 The most effective actions provided by the GP variants.

Figure 6 represents the results of GP analysis which consists of the Weighted, Extended, and Chebyshev solutions respectively. The weighted variant suggests that action No. 3, 4 and 8 are the most suitable for this manufacturer. The extended variant suggests actions No. 1, 4, 5, and 7. The Chebyshev variant suggests action No. 1, 5, and 8. The suitable actions are categorised by GP variant in Figure 7.

Weighted GP (For optimisation)
3. Reduce the number of part numbers carried.

4. Find ways to reduce surplus and obsolete inventory.

8. Improve marketing and sale departments.
Extended GP

(For a mixture between optimisation and balance)
1. Set up a supplier managed inventory program.

4. Find ways to reduce surplus and obsolete inventory.

7. Work with suppliers to improve communications in the supply chain. 
Fig 7 The most effective actions for Silk Manufacturer 1 chosen by different GP models

The actual optimal solutions produced are, of course, dependent on the GP variant used. In conclusion, there are six of the nine actions that appear in at least one of the variant solutions. However, the actions No. 1, 5, and 8 seem to be the most applicable for improving turnover rate whilst maintaining a balance between the different goals as they are derived from the Chebyshev variant. When these optimal solutions were proposed to the manufacturer, the manager suggested that some of the given solutions had been undertaken in part before as the company aimed to boost up the "turnover rate" which is the company's first priority (as shown by the AHP analysis). The manager also points out that they considers the solution No. 1, 5, and 8 to be a new business policy in order to improve sales performance, thus indicating an underlying balancing philosophy consistent with Chebyshev GP.

\section{Conclusions}

This paper has proposed a methodology for the combination of the DEA, AHP and EGP techniques. The general form of this integration is shown by Figure 3, with a level of flexibility included in the actual implementation of the methodology. The analyst can use the information from the initial DEA analysis to inform the subsequent AHP and EGP analyses either indirectly or directly. The indirect case implies using the results of the DEA analysis in a more general way in order to identify weaknesses in the global decision making system that need improvement via the AHP and EGP processes. A more direct route is to specifically target the inefficient units, or units below a threshold efficiency level, for improvement actions via the AHP and EGP processes. The combination of AHP and EGP is more direct, with the AHP being used to identify the relative importance of the criteria for improvement to the decision maker, which give the importance weights to be passed onto the decision maker. It is recommended that a sensitivity analysis with respect to the EGP inclusion parameter (denoted by $\alpha$ in achievement function (7) in this paper) is conducted in order to investigate the balance between efficiency and balance of the objectives.

With regards to the gain in decision support by using the three methods in the manner proposed by this paper, it is necessary to consider the advantage over just using one or two of them in isolation. To just use DEA, or a combination of DEA/AHP, would allow the decision maker to understand the inefficiencies in the system, but not to formulate an effective plan for their resolution according to their set goals and priorities. To use solely AHP, EGP, or a combination of AHP/EGP would allow the decision maker to devise plans to improve individual units, but without the overall understanding of which units should be targeted from improvement or by how much they should be improved. To use a combination of DEA and EGP will give the decision maker both knowledge of inefficiencies and a means to resolve them, but the resulting solution may lack accuracy in its representation of the decision maker's relative weighting of the criteria for improvement. Thus the recommended methodology for holistic decision support is to use all three techniques in the methodological manner given in this paper.

The DEA, AHP, and EGP techniques are used in this paper as representatives of an input-output efficiency measuring technique, a preference elicitation technique, and a multi-criteria decision making technique respectively. These techniques have been chosen as they are the most widely-used technique in their class 
and hence those with the most advanced two-technique combinations in the literature, as described in Section 2.4.4. Each of those techniques could, in principle, be replaced with another technique in its class is this was more appropriate because of say fuzzy data (fuzzy DEA, fuzzy AHP, fuzzy EGP), the need to rank rather than select (ELECTRE), or the need to consider multiple target values or meta-goals (revised GP, meta GP). All of these combinations are promising lines of research for further development of the proposed methodology. It is also recognized that the techniques involved are relative rather than absolute in terms of their calculations of efficiencies and decision maker importance of criteria. Therefore, there exists potential to use the three techniques in an iterative manner in order to improve overall process efficiency.

With regard to the case study, the main objective is to contribute towards using a selection of multi-objective models in order to develop supply chain and inventory strategic models that support the logistics policy decisions of Thai Silk managers. The research starts with a literature review of the area of Thailand textile industry and current supply chain practices. The multiple objectives, constraints, goals and stakeholders involved are systematically categorised. The pertinent data for this analysis is collected from the Thai silk industry. The resulting case study is analysed by the methodology presented in this paper. The DEA analysis suggests improvements are required in the decision making process and configuration of the supply chain and manufacturers' inventory management. A level of symbiosis of the methods is achieved as inefficiencies exposed by the DEA descriptive modeling guides the decision maker responses in the AHP and EGP model formulation process which then leads to prescriptive suggestions for improvement of strategic inventory and supply chain practices. The linkage between AHP and EGP is more formal as the AHP analysis supplies the weights for the EGP model, a process that is well established in the GP literature (Jones and Tamiz, 2010). However, the managerial insight gained in completing the AHP analysis can also assist in their action selection and feedback in the EGP formulation process, a fact that is hitherto not commented on so frequently in the literature.

Overall, the experiences of liaising with decision maker(s) within the Thai silk industry indicates that (i) there is a current a very limited usage of analytical techniques such as those presented in this paper in the industry and (ii) both the process and the results of such techniques is welcomed by the decision makers provided care is taken to translate both into the context of the application area. Of particular note is the disparity between confidence and consistency revealed by the AHP application, which resulted in the need for an automated algorithm to resolve it. This did not detract from the validity or the applicability of the results. In order to accurate model the aspects of companies within the Thai silk supply chain, a combination of both qualitative and quantitative techniques were required. Within the quantitative techniques one descriptive method (DEA) and two prescriptive techniques (AHP, EGP) were utilized. This as an example of mixed modeling methodology being required to provide decision maker support to part of a supply chain. Whilst the case study in this paper pertained to the field of logistics and supply chain management, there is wider applicability of the methodology and the findings of the case study to any decision situation with a set of similar units or processes with different efficiency levels, some of whom require targeted improvements.

\section{References}

Alidrisi, H and Mohamed, S (2012) Resource allocation for strategic quality management: a goal programming approach, International Journal of Quality \& Reliability Management, Vol 29 Iss 3, pp. $265-283$.

Bae, YM and Lee, YH (2011) Integrated risk management process to address the problem of 
assigning pilot missions to Korean army helicopter units, International Journal Of Industrial Engineering-Theory Applications And Practice, Vol 18, pp 151-161. Retrieved from journals.sfu.ca/ijietap/index.php/ijie/article/download/397/198, 02/11/2017.

Balfaqih, H, Nopiah, ZM, Saibani, N and Al-Nory, MT (2016) Review of supply chain performance measurement systems: 1998-2015, Computers in Industry, Vol 82, pp 135-150.

Cavinato, J and Kauffman, RG (2000) Inventory Management, Purchasing Handbook Sixth Edition, New York: McGraw-Hill, Chapter 26.

Charnes, A, Cooper, WW, and Rhodes, E (1978) Measuring efficiency of decision-making units, European Journal of Operational Research, Vol 2, pp 429-444.

Chopra, S and Meindl, P (2007) Supply Chain Management. Strategy, Planning \& Operation. Springer.

Department of International Trade Promotion, (2011) Thai Textile and Apparel Industry, http://www.thaitradeusa.com/home/?page_id=2081 Retrieved $25^{\text {th }}$ July 2017.

Esmaeilikia, M, Fahimnia, B, Sarkis, J, Govindan, K, Kumar, A, and Mo, J (2016) Tactical supply chain planning models with inherent flexibility: definition and review, Annals of Operations Research, Vol 244, pp 407-427.

Gass, SI (1986) A process for determining priorities and weights for large-scale linear goal programmes. Journal of the Operational Research Society, Vol 37, pp 779-785.

Gonzalez-Pachon, J and Romero, C (2003) A method for dealing with inconsistencies in pairwise comparisons, European Journal of Operational Research, Vol 158, pp 351-361.

Garfamy, RM (2006) A data envelopment analysis approach based on total cost of ownership for supplier selection, Journal of Enterprise Information Management, Vol 19 Iss 6, pp $662-678$.

Graham, M (2011) Disintermediation, Altered Chains and Altered Geographies the Internet in the Thai Silk Industry. The Electronic Journal on Information Systems in Developing Countries, Vol 45, Iss 5, pp 1-25. http://www.is.cityu.edu.hk/staff/isrobert/ejisdc/45-5.pdf. Retrieved 02/11/2017.

Hamontree, C (2014) Coordination Buyer-Supplier in Supply Chain Models from Net Present Value Perspective, PhD thesis, University of Portsmouth, UK.

Jablonsky, J (2012) Multicriteria approaches for ranking of efficient units in DEA models Central European Journal of Operations Research, Vol 20, Iss 3, pp 435-449.

Jantaka, C and Tangjaturasopon, A (2012) Barriers of Value Chain for Development of Silk Product in Nakhonchaiburin Zone, Thailand. International Conference on Economics, Business Innovation IPEDR, Vol 38. http://www.ipedr.com/vol38/022-ICEBI2012-A10011.pdf. Retrieved 02/11/2017.

Jadidi O, Cavalieri S and Zolfaghari S (2015) An improved multi-choice goal programming approach for supplier selection problems. Journal of Applied Mathematical Modelling, Vol 39, pp 4213-4222.

Johnsen T and Rhona E (2007) The role of focal suppliers in strategic networks for internationalisation: Perspectives from small and medium- sized Italian and Thai silk suppliers. Journal of Fashion Marketing and Management, Vol 11, pp135 - 147.

Jones, D.F. and Tamiz, M. (2010) Practical Goal Programming, Springer Books, New York. 
Kengpol, A, Tuammee, S. and Tuominen, M (2014) The development of a framework for route selection in multimodal transportation, International Journal of Logistics Management, Vol 25, pp 581-610.

Komolavanij, S (2008) Textiles Supply Chain Development Handbook, In Thai.

Shaw K, Shankar R, Yadav SS and Thakur LS (2012) Supplier selection using fuzzy AHP and fuzzy multi-objective linear programming for developing low carbon supply chain. Expert Systems with Applications, Vol 39, pp 8182-8192.

Lee, AHI, Kang, HY, Lin, CY and Shen, KC (2015) An Integrated Decision-Making Model for the Location of a PV Solar Plant, Sustainability, Vol 7, pp 13522-13541.

Lin Lai, P (2013) A Study on the relationship between Airport Privatisation and Airport Efficiency an Application of Using AHP/DEA Methods. PhD Thesis. Cardiff University, UK. Retrieved from http://orca.cf.ac.uk/46617/, $26^{\text {th }}$ July 2017.

Liu, LB, Berger, P, Zeng, A and Gerstenfeld, A (2008) Applying the analytic hierarchy process to the offshore outsourcing location decision, Supply Chain Management: An International Journal, Vol. 13, Iss 6, pp. $435-449$.

Martin, JC and Roman, C (2001) An Application of DEA to Measure the Efficiency of Spanish Airports Prior to Privatization. Journal of Air Transportation Management, Vol 7, pp 149-157.

Kurttila, M, Pesonen, M, Kangas, J, and Kajanus, M (2000) Utilizing the Analytic Hierarchy Process AHP in SWOT Analysis - a Hybrid Method and its Application to a Forest- Certification Case. Forestry Policy and Economics, Vol 1, pp 41-52.

Milgate, M (2001) Supply chain complexity and delivery performance: an international exploratory study, Supply Chain Management: An International Journal, Vol 6, pp $106-118$.

Ouenniche, J and Tone, K (2017) An out-of-sample evaluation framework for DEA with application in bankruptcy prediction, Annals of Operations Research, Vol 254, pp 235-250.

Patichol P, Winai, W and Lalit, J (2014) Upgrade strategies in the Thai silk industry: balancing value promotion and cultural heritage. Journal of Fashion Marketing and Management Vol 18, pp 20-35.

Petridis, K, Dey, PK and Emrouznejad, A (2017) A branch and efficiency algorithm for the optimal design of supply chain networks, Annals of Operations Research, Vol 253, pp 545-571.

Promsaka Na Sakolnakorn, T (2009) Management Strategy for Administration of Textile Industries in a Developing Country: Case Study Thailand, Journal of Business Case Studies, Vol 5, Iss 3, pp 37-44. Retrieved from https://www.cluteinstitute.com/ojs/index.php/JBCS/article/view/4706/4795, 02/11/2017.

Romero, C. (2001) Extended Lexicographic Goal Programming: A Unifying Approach. Omega, Vol 29, pp 63-71.

(2004) A General Structure of Achievement Function for a Goal Programming Model. European Journal of Operational Research, Vol 153, pp 675-686.

Saaty, TJ (1990) How to make a decision: The analytic hierarchy process. European Journal of Operational Research, Vol 48, pp 9-26.

Schniederjans , M (1995) Goal Programming: Methodology and Applications. Springer. 
Siewsamdangdet P, Vemuri S and Bretherton P (2010), Strategies for sustainable development of silk industry in Northeast Thailand, International Journal of Strategic Management, Vol 10, Issue 1. Available from http://ijsm-journal.org/domains/IJSM-JOURNAL/Default.aspx. Accessed 02/11/2017.

Song, DP (2013). Optimal Control and Optimization of Stochastic Supply Chain Systems. Springer, London.

Wang G, Huang, SH, and Dismukes, JP (2004) Product-driven supply chain selection using integrated multi-criteria decision-making methodology. International Journal of Production Economics, Vol 91, pp 1-15.

Watchravesringkan, K, Karpova E, Hodges NN and Copeland R (2009) The competitive position of Thailand's apparel industry: Challenges and opportunities for globalization. Journal of Fashion Marketing and Management, Vol 14, pp 576-597.

Yadav, V and Sharma, MK (2015) An application of hybrid data envelopment analytical hierarchy process approach for supplier selection, Journal of Enterprise Information Management, Vol 28 pp 218-242.

Yearman, K and Gluckman, A (2005) Falling off a cliff. Dollars \& Sense, http://www.dollarsandsense.org/archives/2005/0905yearman.html, Retrieved 26th July 2017.

Zaim, S, Turkyilmaz, A, Acar, MF, Al-Turki U, and Demirel O (2012) Maintenance strategy selection using AHP and ANP algorithms: a case study. Journal of Quality in Maintenance Engineering, Vol 18, Iss 1, pp 16-29.

Zhu, J (2016) Data envelopment analysis, a handbook of models and methods, Springer, New York. 